\title{
Visualización de redes personales en Sarajevo
}

\author{
Claudia Aguilar - UAB - Antropología Social i Cultural ${ }^{1}$
}

\section{Resumen}

El concepto de "identificación" permite a las Ciencias Sociales, más que el de "identidad étnica", analizar los procesos mediante los cuales las personas se autoidentifican e identifican a otros. A través del estudio de las redes personales de jóvenes en Sarajevo (Bosnia y Herzegovina) se muestran diferentes procesos de identificación en un contexto de fuerte exclusión étnica. La visualización de las redes personales por parte de los propios informantes constituye una fuente privilegiada de investigación.

Palabras clave: identificación, Balcanes, redes personales, Egonet.

\section{Abstract}

The concept of "identification" allows Social Sciences, better than the concept of "ethnic identity", to analyze the process by which people identify themselves and identify others. Through the study of the personal networks of young people from Sarajevo (Bosnia and Herzegovina) different processes of identification are shown in an ethnic exclusion context. The visualization of personal networks by the informants is a privileged source of research.

Keywords: identification, Balcans, personal networks, Egonet.

\section{I ntroducción}

La investigación que presentamos en este artículo surge de la insatisfacción con los términos utilizados desde la Antropología y demás Ciencias Sociales para describir el modo que tienen las personas de agruparse o de agrupar a otros en grupos. En Bosnia y Hercegovina $(\mathrm{BiH})$ el discurso oficial o hegemónico divide a los ciudadanos en serbios, croatas y bosníacos o musulmanes y los fuerza a situarse de manera casi obligatoria en una de estas tres categorías excluyentes regeneradas en un contexto de guerra. Pero en una sociedad urbana como la de Sarajevo, estas simples y supuestamente antiguas distinciones identitarias impuestas aparecen difusas y no permiten explicar su complejidad. Resulta entonces importante distinguir de manera clara entre las categorías de práctica y las categorías de análisis (Cf. Bourdieu, 1977). De las categorías de práctica es relevante mostrar que, aunque son utilizadas por los actores sociales, esto no significa que tengan una existencia esencial: han surgido de alguna parte y por alguna razón, en un contexto político y social determinado, aspecto que no debe ser obviado para poder comprender la realidad social en un determinado momento.

\footnotetext{
${ }^{1}$ Enviar correspondencia a: claudia.aguilar@uab.es
} 
Que existan tales categorías y se utilicen en la vida cotidiana no significa que la gente sea "serbia", "bosníaca" o "croata". Hay personas que se niegan a utilizarlas, que no quieren entrar en esta postguerra terminológica y resulta por ello necesario un análisis más profundo de la cuestión, aunque en los discursos políticos se hable de "etnias" dándoles estatus de grupos reales.

Sin embargo, desde una perspectiva académica debemos superar estos discursos políticos o ideológicos y no utilizar sus categorías de práctica, las cuales están destinadas a crear determinadas "realidades" sociales. Tenemos que situarnos en otra perspectiva y dar un paso más para analizar y contextualizar tales categorías.

El concepto de etnia, al igual que el de cultura, es amplio y vago, por lo que es muy fácilmente utilizable por el discurso político. El mismo discurso es posteriormente utilizado a su vez por los ciudadanos para construir su imaginario social. Por ejemplo en Bosnia, antes de la reciente importación del concepto de etnia (mediante constructos como "guerra étnica" o "limpieza étnica"), no había etnias sino nacionalidades o pueblos (narod, narodnosti). La aplicación de tales conceptos foráneos, juntamente con un proceso de redefinición subsiguiente al conflicto bélico, ha ayudado a reforzar la distinción entre grupos. Respecto a la identidad, utilizaremos el término "identificación" como lo han hecho otros autores (Brubaker $\&$ Cooper, 2000, De Federico, 2004). Este término ilustra mejor el hecho de que la identificación es un proceso social que depende del contexto y la situación. De igual manera nos permite diferenciar entre la auto-identificación y la identificación por otros.

La identificación de las personas, tanto la auto-identificación como la identificación por otros es relacional, es decir, se crea constantemente a través de las relaciones sociales. Por ello consideramos interesante el estudio de las redes personales, ya que pueden aportarnos mucha información acerca de la realidad cotidiana de la persona, que es el ámbito en el cual se "negocian" constantemente las identificaciones colectivas.

\section{Antecedentes}

La fase previa de este estudio, realizada en Sarajevo en el 2003, se centró en un grupo de jóvenes de la ciudad. En esta primera aproximación llevamos a cabo una observación participante de cuatro meses y probamos la metodología de análisis de las redes personales con 17 casos en profundidad, los cuales, pese a no constituir una gran muestra, fueron suficientes para obtener una preciosa información que 
nos llevó a la formulación de nuevas hipótesis y al desarrollo de un diseño de investigación más completo.

Aquellos primeros resultados nos proporcionaron información sobre qué términos se utilizaban en Sarajevo para clasificar a las personas de BiH en diversos grupos, el uso de tales categorías, las líneas discursivas sobre la ontología de las mismas y la relación entre el uso de determinadas categorías, los discursos sobre la identificación y, por último, la etnicidad y las redes personales.

Igualmente, pudimos constatar la existencia de una relación entre los discursos que sostienen las personas y las categorías étnicas que utilizan tanto para clasificar a los demás como para auto-identificarse. Asimismo, encontramos que los jóvenes que se autodenominaban "bosnios" jugaban un rol importante en la red de relaciones multiétnicas, en la que los lazos fuertes, sorprendentemente, eran muy importantes (en un contexto de segregación "étnica"). Finalmente hallamos una relación entre la composición de las redes personales y los discursos étnicos sostenidos, de forma que las redes más diversas podían contener múltiples identificaciones, mientras que las redes más densas llevaban asociados discursos étnicos excluyentes.

\section{Objetivos de la presente investigación}

La presente investigación persigue, en consecuencia, analizar la complejidad que envuelve todo el proceso de identificación. Por ello nos basamos en una concepción de la identificación que pretende superar la idea de una sola identidad esencial, heredada y basada en la sangre y concebirla como un proceso en negociación constante y colectiva a través de las relaciones personales en los diversos contextos y situaciones. El estudio se centra en las redes de relaciones sociales de los jóvenes de Sarajevo y en sus discursos identitarios para captar sobre qué premisas se está construyendo la sociedad futura del nuevo país surgido de la guerra.

Tratamos de recoger información para:

- Analizar cómo son las relaciones personales de los jóvenes de Sarajevo para saber si siguen criterios de "división étnica", si las categorizaciones oficiales moldean realmente las auto-identificaciones o auto-percepciones, en qué casos y de qué manera. 
- Analizar los procesos de identificación personal entre los jóvenes de Sarajevo, intentar ir más allá de la "identidad étnica” y recoger qué conceptos utilizan para identificarse e identificar a las personas de su red personal.

- Observar si seguimos encontrando una relación entre el modo de identificarse y el tipo de red personal.

- Constatar si la gente que hace de puente entre grupos diversos, que tiene por lo tanto acceso a diferentes discursos y cosmovisiones (Buró, 2004), tiene más opciones de elegir y por ello va a utilizar en menor medida el discurso hegemónico para auto identificarse.

- Analizar las características de las personas que no siguen el discurso mayoritario y se niegan a identificarse mediante las categorías étnicas excluyentes.

La metodología seguida se expone a continuación.

\section{Metodología}

Para lograr los objetivos mencionados hemos elaborado un cuestionario con el programa Egonet, desarrollado por McCarty (2003), que consta de dos partes.

En la primera planteamos una serie de preguntas (unas 50) personales al informante (lo llamaremos EGO pues es la terminología que se utiliza al hablar de redes personales o egocéntricas) entre las que incluimos algunas referentes a la auto-identificación de EGO como las siguientes:

- Te identificas (te sientes parte) con una de las siguientes comunidades? (respuestas; Serbios, Croatas, Musulmanes/bosníacos, yo no me identifico con estas categorías).

- Te voy a pedir que escribas TRES localidades (pueblo, ciudad, etc) regiones, países u otros territorios (como Europa) o comunidades (religiosa, profesional, amistad, etc) que están relacionadas con tu vida, a las que te sientas ligado/a o que consideres importantes para definirte o identificarte.

- Escribe lo que primero responderías en la frase "yo soy..."

En la segunda recogemos toda la información necesaria para elaborar la red personal del informante. Técnicamente se trata de elaborar una lista de 45 personas conocidas de Ego. McCarty (2002) sugiere que, tratándose de una lista 
libre de personas de todas las categorías, 45 son suficientes, ya que el hecho de ser una lista de libre generación tiene a generar los lazos íntimos al principio pero es suficientemente larga para obtener información de las diferentes áreas de la estructura de la red personal (lazos débiles).

A continuación, de cada una de las 45 personas se preguntan una serie de atributos como género, edad, lugar de residencia, lugar de nacimiento, nivel de estudios, ocupación, religión, intensidad de la relación (desde íntimos hasta conocidos), tipo de relación (familia, amigos, trabajo, etc.) y tres preguntas sobre identificación:

- ¿Forma él/ella parte de una de las siguientes comunidades? Respuestas: Serbios, Croatas, Musulmanes/Bosníacos. Estas categorías no tienen sentido para mí.

- En relación contigo, sientes que él/ella:

Forma parte de otra comunidad y diferente de mí.

Forma parte de otra comunidad pero no considero que es diferente.

No me doy cuenta de que es de otra comunidad.

Forma parte de mi comunidad.

Forma parte de mi comunidad pero es diferente de mí.

Estas diferencias no tienen sentido para mí.

- ¿Cómo crees que él/ella te considera a ti? Respuestas: Serbio, Croata, Musulmán/Bosníaco, Estas categorias no tienen sentido para él/ella.

Por último se pregunta quién conoce a quién de entre los 45, información que resultará básica para poder elaborar la red personal y obtener medidas estructurales.

Una vez procesada la información recogida y obtenida la red personal del informante, el último paso es mostrar la red al informante para recoger la información que surge de la visualización de la red personal y los atributos de las personas de la red.

Esta última parte resulta clave pues durante la entrevista que sigue a la visualización se recoge una información de carácter cualitativo relevante para poder entender los argumentos que guían la elección de una u otra respuesta del cuestionario. En una investigación reciente sobre los efectos de la visualización de las redes personales (McCarty et al. 2005) pudimos constatar que la visualización de las redes personales con el informante nos proporciona información adicional y detalles de la realidad social del informante que de otra manera difícilmente podrían obtenerse. 


\section{Visualización de las redes personales}

Vamos a mostrar tres ejemplos de redes personales, obtenidas mediante el programa Egonet, con algunos atributos tal y cómo las mostramos a los informantes.

La primera red que solemos comentar es la del tipo de relación (ilustración 1) pues de esta manera se sitúan con bastante claridad los diversos grupos que forman parte de la red personal. A continuación se comentan el resto de variables incidiendo en los temas que son clave para nuestra investigación. Los ejemplos que vamos a ver aquí son las redes que representan las variables que tienen relación con el tema que nos ocupa, la identificación.

\section{a) Sabina}

El primer ejemplo es el de Sabina, una historiadora de unos 30 años, de Sarajevo, casada y con un hijo. Se auto identifica como musulmana o bosníaca y el Islam es un aspecto muy importante de su vida.
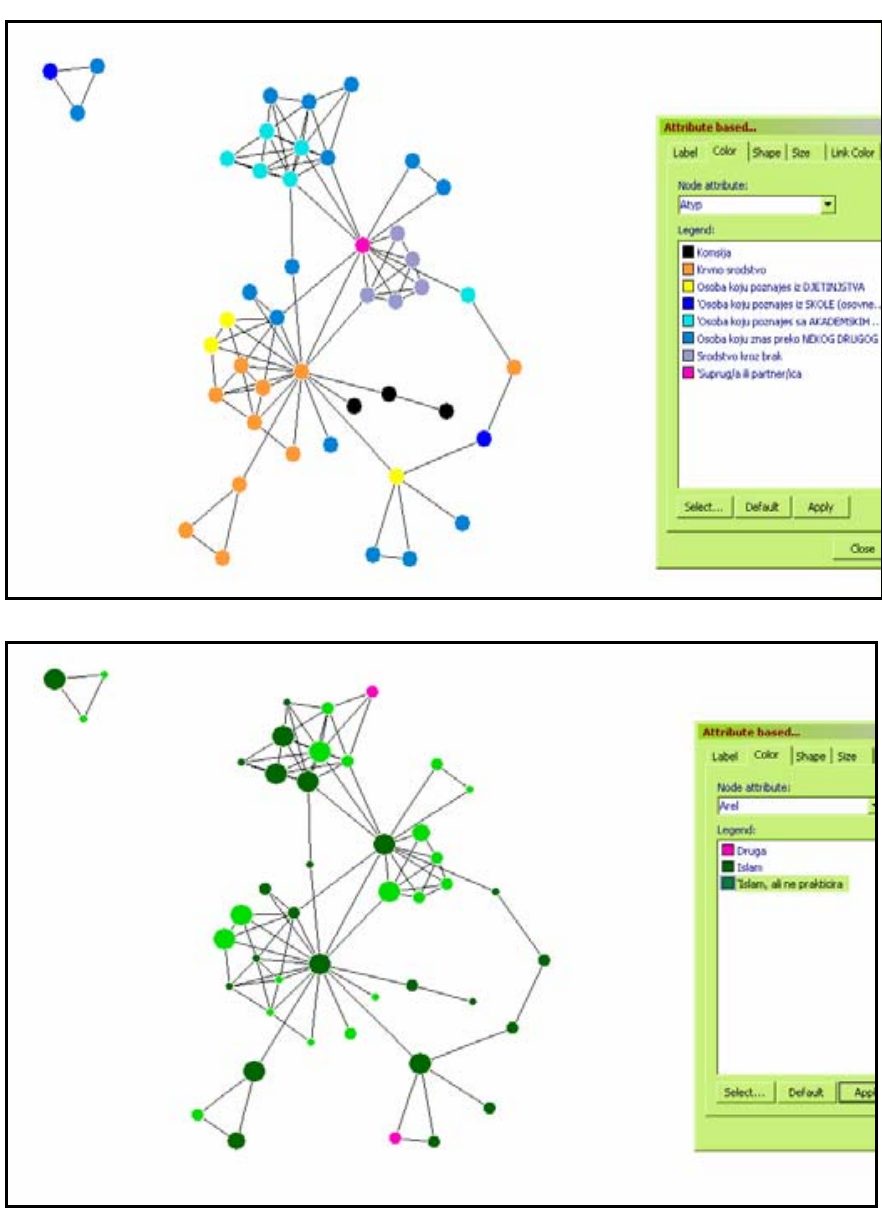

I lustración 1. Tipo de relación entre ego y alteri (Negro: Vecinos; Naranja: Familia; Amarillo: personas que conoce de la infancia; Azul oscuro: escuela; Azul cielo: actividades académicas,; Azulón: personas que conoce a través de alguien; Lila: familia política; Rosa: esposo/ a o pareja.

I lustración 2. Religión de los alteri

(Rosa: otra, Verde oscuro: Islam; Verde claro: Islam no practicante 

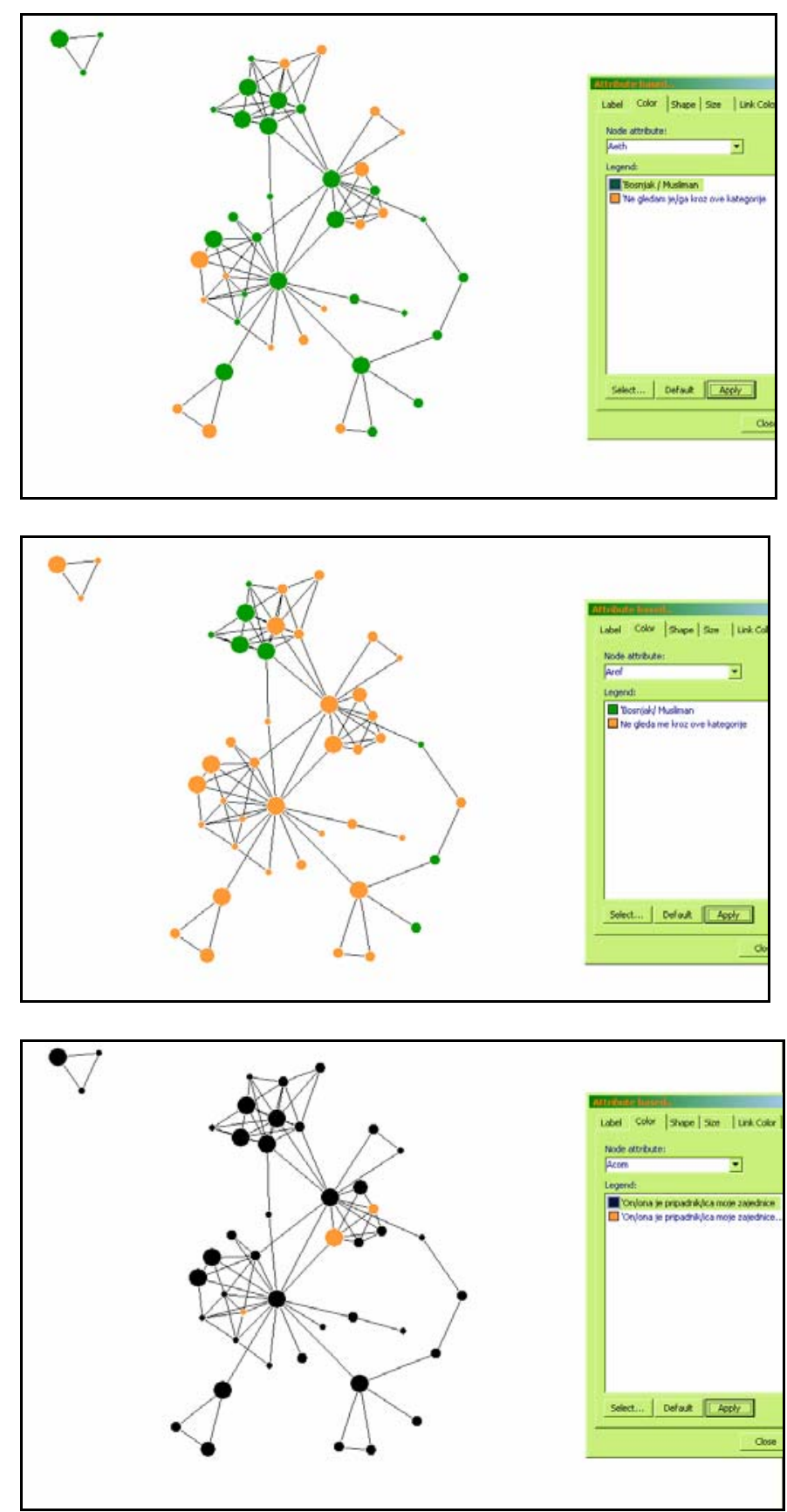

I lustración 3. Etnicidad de los alteri (Verde: Musulman/Bosníaco; Naranja: Estas categorías no tienen sentido para mí.

I lustración 4. Etnicidad reflexiva (Verde: Musulmán/Bosníaco; Naranja: Estas categorías no tienen sentido para él/ella.

I lustración 5. Comunidad (Negro: Forma parte de mi comunidad; Naranja: forma parte de mi comunidad pero es diferente de mí.

En la Ilustración 2 podemos ver que prácticamente la totalidad de la red de Sabina está formada por personas que practican en mayor o menor medida el Islam. Las dos personas calificadas de "otra" son hijos de matrimonios mixtos, bastante frecuentes en Yugoslavia.

En la Ilustración 3 podemos ver que Sabina no considera a todas las personas de su red pertenecientes a la comunidad musulmana o bosníaca sino hace una diferenciación a partir de un criterio propio y que no sigue el discurso hegemónico de considerar a todos los musulmanes bosníacos en el sentido "étnico". Su argumentación para justificar la no inclusión de estas personas en la comunidad 
bosníaca es que tales personas de una u otra manera no siguen los preceptos del Islam como ella los entiende.

Resulta curioso entonces que cuando se trata de decir cómo cree ella que la consideran estas personas ${ }^{2}$ (Ilustración 4) nos diga que la mayoría de personas de su red no la consideran según tales categorías excepto unas pocas que, según Sabina, tienen el Islam muy presente y ven a todo el mundo según tales categorías.

La última red (Ilustración 5) nos muestra qué personas considera de su comunidad: todas son consideradas parte de su comunidad excepto unas pocas a las que considera diferentes de ella. Al preguntarle por ello, nos explicó que se trata de integrantes de su familia política que viven al norte de Bosnia, cerca de Croacia y que cuando convivió con ellos un tiempo descubrió con horror que aún siendo musulmanes comían cerdo sin problemas. No nos pudo explicar por qué no consideraba de igual manera a sus amigos de la red que beben alcohol, viven en pareja sin casarse y no piensan poner un nombre musulmán a sus hijos.

En todo lo explicado anteriormente encontramos grandes contradicciones y piezas que no encajan, pero en esto reside precisamente el interés de este tipo de análisis, el cual nos permite ver que cada persona tiene una manera propia de situarse y de situar a los otros en el mundo.

b) Ranko

A continuación se muestra el ejemplo de Ranko un joven economista de Sarajevo que a raíz de la guerra tuvo que trasladarse con su familia a Lukavica, población cercana que ha quedado en la parte serbia de $\mathrm{BiH}$ y que se ha convertido en la parte serbia de Sarajevo (Srpsko Sarajevo). Se autoidentifica como Serbio.

En este caso podremos constatar cómo tanto las redes como las argumentaciones de Ranko siguen perfectamente el discurso etnicista hegemónico en Bosnia, basado en la identificación excluyente.

\footnotetext{
2 Por "etnicidad reflexiva" entendemos cómo cree EGO que cada uno de sus alteri el/la considera respecto a la pertenencia o no a uno de los tres grupos étnicos.
} 

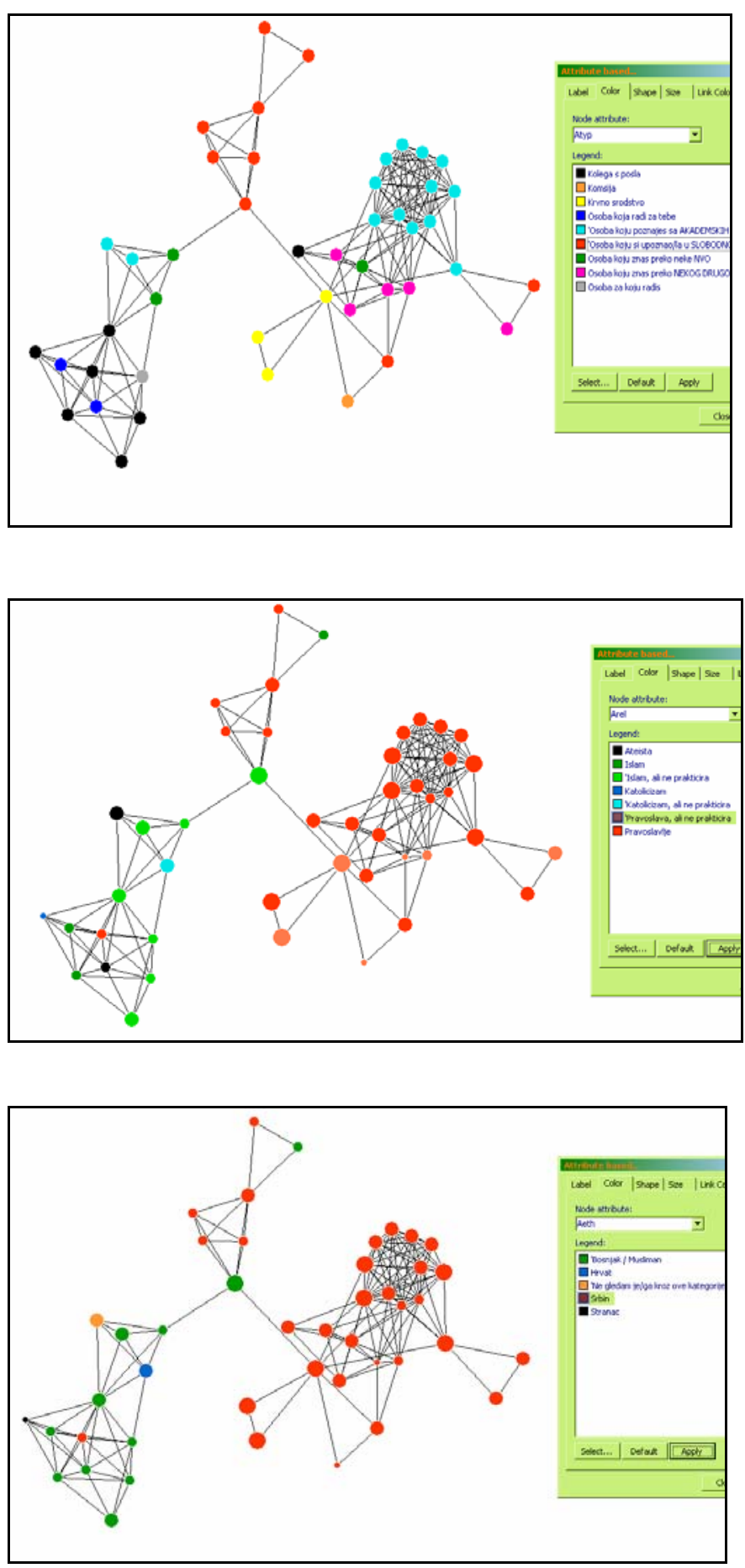

Ilustración 6. Tipo de relación entre ego y alteri (Negro: Colegas de trabajo; Naranja: vecinos; Amarillo: familia; Azul oscuro: personas que trabajan para él; Azul cielo: actividades académicas; Rojo: tiempo libre; Verde: conoce a través de ONG; Rosa: personas que conoce a través de alguien; Lila: jefe.

Ilustración 7. Religión de los alteri (Negro: ateo/a; Verde oscuro: Islam; Verde claro: Islam no practicante; Azul oscuro: Catolicismo; Azul claro: Catolicismo no practicante; Rojo: Ortodoxo; Naranja: Ortodoxo no practicante.

I lustración 8. Etnicidad de los alteri (Verde: Bosníaco / musulmán; Azul: Croata; Rojo: Serbio; Negro: extranjero; Naranja: Estas categorías no tienen sentido para mí. 

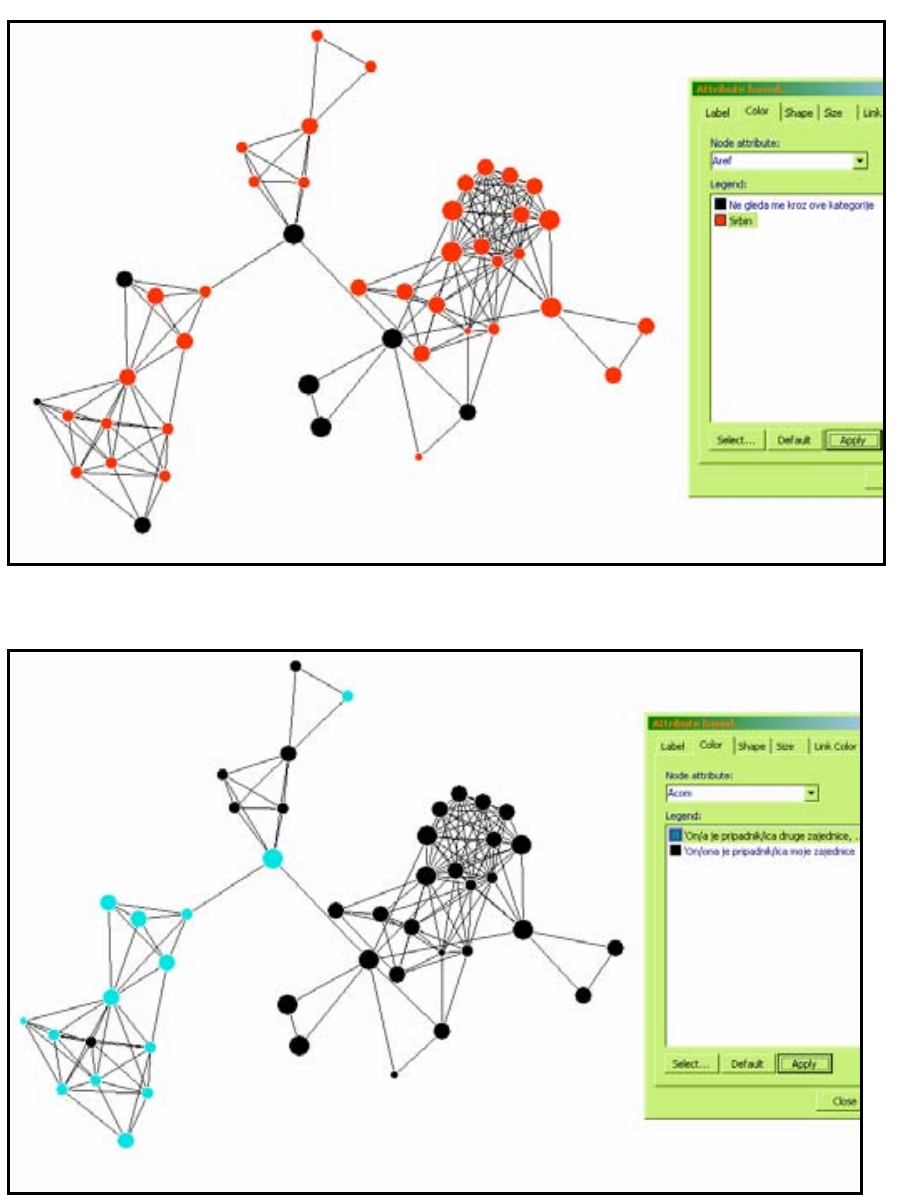

Ilustración 9. Etnicidad reflexiva (Rojo: Serbio; Negro: estas categorías no tienen sentido para él/ella).
Ilustración 10. Comunidad (Azul: Forma parte de otra comunidad pero no considero que es diferente, Negro: forma parte de mi comunidad).

En la Ilustración 6 vemos que su red está dividida en tres grandes grupos: el del trabajo (trabaja en una organización internacional en el centro de Sarajevo), el de amigos de ocio y el de personas que viven en su parte de la ciudad (Sarajevo serbio) formado por vecinos, familia y amigos de la universidad.

Si comparamos las Ilustraciones 7 y 8 podemos ver que para Ranko la religión es sinónimo de etnicidad o pertenencia a una determinada comunidad. Asimismo vemos que su círculo íntimo esta formado por serbios mientras que la heterogeneidad de la red viene solo de sus colegas de trabajo y un par de amigos de tiempo libre, uno de ellos podemos ver que conecta los tres "mundos" de Ranko, que estarían completamente separados sin esta persona.

En cuanto a su percepción de cómo lo consideran los demás (ilustración 9) él cree que la práctica totalidad de su red lo califica de serbio, excepto su familia nuclear y su pareja. 
Respecto a la pertenencia o no a su comunidad encontramos el mismo discurso: sólo los serbios forman parte de su comunidad, mientras que el resto no son de su comunidad pero no los considera diferentes de él.

c) Suad

El último ejemplo se muestra muy distinto del anterior. Se trata de Suad que, como Ranko, trabaja como traductor en una organización internacional en Sarajevo, aunque él no es originariamente de Sarajevo sino del norte de Bosnia.

En la Ilustración 11 podemos ver que su red también se divide entre relaciones del trabajo y el resto, pese a que, contrariamente a Ranko, eso no provoca una división étnico-religiosa de su red. En la Ilustración 12 podemos ver que nos encontramos ante una red muy heterogénea con representantes de todas las religiones, aunque con una mayoría de ateos. Él mismo también se considera ateo.

Suad ni cree ni apoya las distinciones "étnicas" en Bosnia, tal como se puede ver en la Ilustración 13, aunque vemos que las sigue manteniendo para ciertas personas de su red. Su explicación es que estas personas son nacionalistas y muestran constantemente su pertenencia a una u otra comunidad y por ello le resulta difícil no verlas en estos términos.

Son algunas de estas mismas personas las únicas que lo ven a él como musulmán (Ilustración 14): nadie más en su red, ni tampoco él mismo, lo considera parte de tal comunidad.

En este caso, su concepto de comunidad (Ilustración 15) dista del de "comunidad étnica". La pertenencia a la comunidad según Suad no pasa por pertenecer a uno u otro grupo étnico sino por sentir a las personas más o menos cercanas.

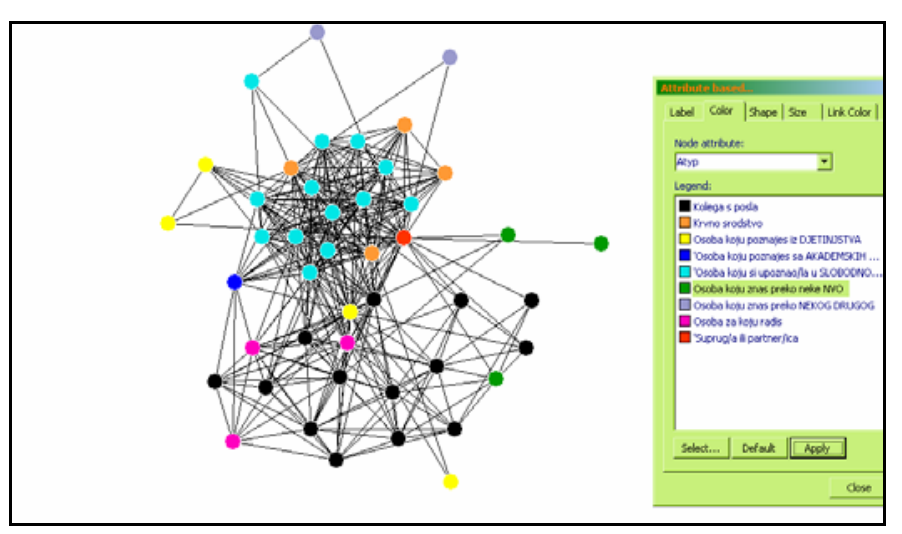

I lustración 11. Tipo de relación entre ego y alteri (Negro: colegas de trabajo; Naranja: familia; Amarillo: amigos de la infancia; Azul oscuro: actividades académicas; Azul cielo: tiempo libre; Verde: conoce a través de ONG; Rosa : jefes; Lila: conoce a través de terceros; Rojo: pareja. 

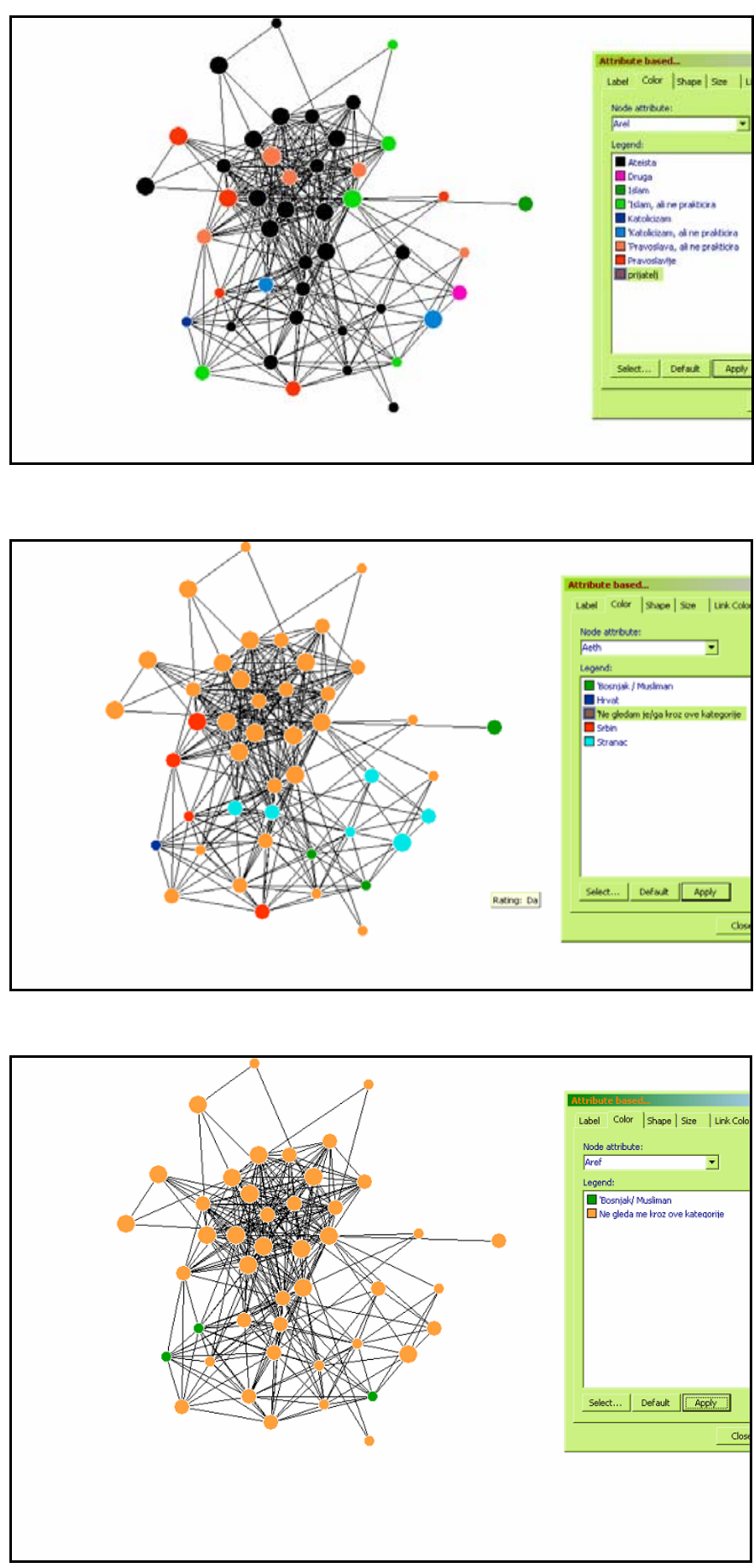

I lustración 12. Religión de los alteri (Negro: ateo/a ; Verde oscuro: Islam; Verde claro: Islam no practicante; Azul oscuro:

Catolicismo; Azul claro: Catolicismo no practicante; Rojo: Ortodoxo; Naranja: Ortodoxo no practicante; Rosa: otra)

I lustración 13. Etnicidad de los alteri (Verde: Bosníaco / musulmán, Azul oscuro: Croata, Rojo: Serbio, Azul claro: extranjero, Naranja: Estas categorías no tienen sentido para mi.

I lustración 14. Etnicidad reflexiva (Verde: Musulmán/Bosníaco; Naranja: Estas categorías no tienen sentido para él/ella) 


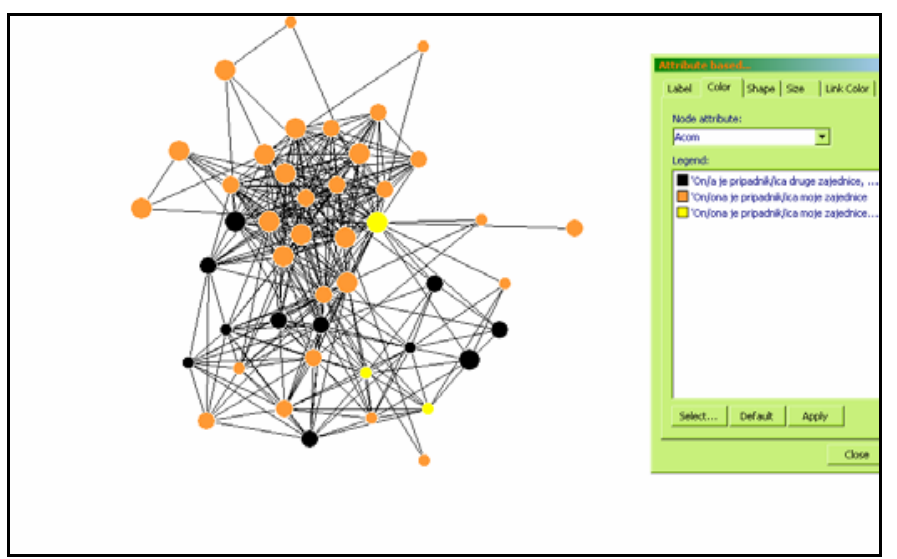

I lustración 15. Comunidad (Negro: Forma parte de otra comunidad pero no considero que es diferente; Naranja: forma parte de mi comunidad; Amarillo: forma parte de mi comunidad pero es diferente de mí)

\section{Conclusión}

Hemos podido ver que con tan sólo en tres ejemplos podemos encontrar una rica diversidad en cómo la identificación o pertenencia es percibida o sentida. Cada uno da su propio significado a los conceptos étnicos: no todos los quieren utilizar ni considerar de igual manera. Además, el concepto de comunidad tiene diferentes significados para personas diversas.

Podemos también afirmar que la introducción de la visualización de las redes personales en los diseños de investigación nos puede aportar mucha información sobre la vida cotidiana de las personas y, específicamente en nuestra investigación, sobre la auto-identificación y la identificación de otros y por otros, mucho mayor que una simple entrevista donde la mayoría de las veces las gente te dice aquello que quieres escuchar. Por lo menos así sucede en Bosnia y Hercegovina, donde la gente está acostumbrada a tratar con las organizaciones internacionales. La mayoría de organizaciones tratan de manera acrítica las categorías étnicas y proponen talleres y seminarios para "concienciarse" de la propia etnicidad y establecer vínculos con los "otros" para así caminar hacia la reconciliación.

Podemos acabar diciendo que la identificación o pertenencia es un tema complejo que no puede ser reducido a tres conceptos excluyentes como los de "Serbio", "Croata" o "Bosníaco". Esperamos que a través de este estudio podamos dar un paso más en la comprensión de esta complejidad. 


\section{Bibliografía}

Aguilar, C; Molina, J.L. (2004). “Identidad étnica y redes personales entre jóvenes de Sarajevo", Vol.7,\#6, Oct./Nov. 2004. Volumen conjunto de REDES y Araucauria. Revista I beroamericana de Filosofía, Política y Humanidades.

Brubaker, R \& Cooper, Frederick (2000). Beyond "identity". Theory and Society, 29, 1-47.

Burt, Ronald (2004). "Structural Holes and Good Ideas". American Journal of Sociology, 110(2), 349-399.

de Federico, Ainhoa. (2004) "Redes de identificación con Europa: amistad e identidades de estudiantes europeos". Tesis doctoral en cotutela. Université des Sciences et Technologies de Lille, France. Universidad Pública de Navarra, Espagne.

McCarty, C; Molina, JL; Aguilar, C; Rota, L (2005).<"A comparison of social network mapping and personal network visualization", Field Methods (en prensa).

McCarty, Chris (2002). "Structure in Personal Networks", JoSS. <http://www.library.cmu.edu: 7850/JoSS/McCarty/McCarty.htm> [Visitado: 25-0302].

McCarty, Chris (2003). Egonet. Personal Network Software <http://survey.bebr.ufl.edu/EgoNet/> [Visited: 2-3-04]. 